\title{
EL INCIERTO SENTIDO DEL TRABAJO EN LA SOCIEDAD DE RIESGO GLOBAL
}

THE UNCERTAIN MEANING OF WORK IN A GLOBAL RISK SOCIETY

\author{
Juan A. Roche Cárcel \\ Universidad de Alicante (España) \\ ja.roche@ua.es
}

Recibido/Received: 02/12/2012

Modificado/Modified: 04/02/2013

Aceptado/Accepted: 27/04/2013

\section{RESUMEN}

Partiendo de los objetivos propuestos, el artículo pone de manifiesto la profunda crisis estructural en la que ha entrado el trabajo en la Posmodernidad. Esto ha supuesto, la pérdida de su seguridad en el contexto del cuestionamiento de la prosperidad de la economía, del Estado de Bienestar, del propio Estado y de la democracia. Cierto, el trabajo se presenta hoy con riesgo, precario, inseguro, incierto, desespacializado, fragmentado, acelerado, flexible, desregulado, informalizado, impactado por las nuevas tecnologías, "brasileñizado", jerarquizado, desigual, individualizado y con el carácter corroído del trabajador. De esta forma, el trabajo se desvaloriza, se convierte en ilegible y pierde su sentido. Además, si se tiene en cuenta que los remedios puestos encima de la mesa en Occidente son claramente insuficientes y poco creativos, parece que nos encontremos ante el colapso o el final de una etapa, del trabajo, del propio capitalismo y del Estado social-liberal-democrático.

\section{PALABRAS CLAVE}

Sociología del trabajo, sentido del trabajo, calidad de la democracia, incertidumbre, riesgo.

\section{SUMARIO}

1. Introducción. 2. La evolución del trabajo en la Modernidad. 2.1. La conmoción del trabajo en la evolución Industrial. 3. La crisis del trabajo en la sociedad contemporánea. 4. Las transformaciones en la estructura ocupacional y sus consecuencias. 5. Las características del trabajo en la actualidad. 6. Análisis de algunas alternativas ante la crisis del trabajo. 7. Reflexiones finales. Bibliografía.

\begin{abstract}
Based on proposed objectives, this article shows the deep structural crisis in which work is involved in Postmodernity. That has meant the loose of security in the context of the weakness of the economic prosperity, the Welfare State, the State itself and the Democracy. Certainly, nowadays work appears as risky, precarious, insecure, uncertain, without a defined space, fragmented, accelerated, flexible, unregulated, informal, hit by new technologies, "brasilianizated", hierarchical, unequal, individualized and the reason of the corroded character of the worker. Thus work gets devaluated, becomes illegible and lost its sense. Moreover, if we consider that the solutions put on the table by Occident are clearly insufficient and uncreative, it seems that we are facing the collapse or the end of an era, of the work, of the capitalism itself, and even the social-liberal-democratic State.
\end{abstract}

\section{KEYWORDS}

Sociology of work, mean of work, democracy quality, uncertainty, risk. 


\section{CONTENTS}

1. Introduction. 2. The evolution of work in Modernity. 2.1. The shock of work in the Industrial Revolution. 3. The crisis of work in contemporary society. 4. The changes in the occupational structure and its consequences. 5. Work characteristics today. 6 . Analysis of some alternatives to the work crisis. 7. Final thoughts. References.

\section{INTRODUCCIÓN}

En la historia occidental el concepto de trabajo ha tenido muy mala prédica (Tezanos, 2001:11-2). Por ejemplo, en la Antigüedad, no es bien considerado y prueba de ello lo constituye el origen etimológico del término que procede de la palabra latina "Tripaliare" y de su derivado "Tripalium", un instrumento de tortura; el trabajo supone, pues, para los antiguos una tortura. Tampoco es que la Biblia tenga una mejor opinión de lo que representa para la existencia humana, ya que el libro sagrado maldice la actividad laboral, como se expresa cuando Adán y Eva son expulsados del paraíso y, consecuentemente, condenados a trabajar con su esfuerzo y sudor en un mundo hostil y lleno de dolor. A partir de los monasterios medievales y del Renacimiento y, sobre todo, desde la Revolución Industrial el trabajo es revalorizado paulatinamente. Pero Marx, le da otro golpe de gracia a su estimación, al considerarlo únicamente como una mercancía similar al azúcar con la que el obrero puede costear su sustento y, por tanto, sobrevivir (Marx, 1985:9). Y es que, de la visión marciana, se deduce que la vida y el trabajo se han disociado, pues éste, al ser tratado como un valor de cambio más que de uso, ha sido nuevamente desvalorizado.

Ecos de este desprestigio perviven en la actualidad, en un momento de crisis profunda o tal vez de cambio de época -como se verá más adelante-, en la que el trabajo ha dejado de ser lo que era y en la que significa para muchos ciudadanos y ciudadanas -cuando, en el mejor de los casos, tienen un empleo- una ardua tarea que se ven obligados a desarrollar dadas las difíciles y, en ocasiones, angustiosas condiciones laborales. Éstas son el resultado de una época en la que el capital ya no cuenta con enemigos y en la que está muy ensoberbecido de poder; en la que ha perdido gran parte de su talante y ética humanos; y en la que ha situado al trabajo como una actividad ansiolítica, precaria, inestable y de alto riesgo que produce profundas heridas físicas y psicológicas, cada vez más abismales desigualdades sociales y un corrosivo deterioro del sentido de la vida.

Este escenario es tanto más triste cuanto que el significado del trabajo tiene que ver con el desarrollo de la individualidad, con el sentido vital y con los estilos de vida. Ahora bien como se va a ir viendo a lo largo de este artículo-, estas funciones están siendo muy transformadas en la sociedad contemporánea, precisamente porque el trabajo ha entrado en crisis y, con él, el modelo específico de sociedad y de civilización en la que ocupa un papel esencial, su patrón como empleo, su conexión con las relaciones salariares y su concepción como actividad social (Tezanos, 2001:28-232).

Precisamente, los objetivos generales de este artículo tratan de $\left(1^{\circ}\right)$ analizar el estado actual del trabajo en las sociedades occidentales y cómo ha llegado a ser lo que es, $\left(2^{\circ}\right)$ reflexionar acerca del concepto de trabajo y de democracia en la que éste se sustenta y $\left(3^{\circ}\right)$ anticipar algunas cuestiones referentes a si es posible reformar el sistema y encontrar soluciones o, si por el contrario, éstas no parecen probables y, más bien, lo que manifiestan 
es que hemos llegado a un final de etapa de contornos más o menos imprecisos, más o menos catastróficos.

\section{LA EVOLUCIÓN DEL TRABAJO EN LA MODERNIDAD}

Pero, ¿cómo ha llegado a ocurrir esta crisis del trabajo? Desde una perspectiva de proceso civilizatorio, es el resultado de un largo desarrollo de alongué durée en el que los humanos se han empeñado, con un cierto éxito, en sacarle el mayor provecho a los recursos naturales con el menor esfuerzo posible. Esto se ha logrado en tres grandes etapas: la de la Revolución Neolítica, basada en las herramientas; la Industrial, sustentada en las máquinas; y, la Tecnológica, apoyada en los robots industriales y la informática (Tezanos, 2001:47). Estos sucesivos instrumentos, además de disminuir la cantidad de energía física corporal puesta a disposición, han aumentado los procesos de abstracción, alejando al ser humano de su cuerpo y de la naturaleza. De manera que, al mismo tiempo que ha dominado prácticamente al planeta entero en beneficio propio, lo ha agotado y lo ha dejado en tal estado de precariedad que ha puesto en riesgo la vida humana misma. Así, la crisis del trabajo se incardina también con la de la Tierra y con una manera de ser y estar en ella, de insertar al ser humano y a su cuerpo con el entorno.

\subsection{La conmoción del trabajo en la Revolución Industrial}

Concentrándonos en la idea del trabajo, se puede decir que se ha pasado bastante rápidamente de una fase moderna, caracterizada por la progresiva estabilidad y seguridad, a una posmoderna, en la que se ha precipitado y consolidado la crisis, agudizándose en los últimos años con los graves problemas financieros y de deuda soberana. La Modernidad propiamente dicha es el período que va, fundamentalmente, de 1890 a 1930 (Bell, 1992: 117), aunque se alarga hasta la década de los 60, cuando surge, tras la crisis del petróleo de 1973, una nueva etapa denominada Posmodernidad. Pues bien, el acontecimiento más trascendental de la Modernidad, en lo que al trabajo se refiere, es la Revolución Industrial del siglo XIX. Este acontecimiento va asociado a los experimentos científicos, a los cambios energéticos (en el carbón y el vapor) y a un nuevo espíritu empresarial innovador, auténticos catalizadores (Gratton, 2012:20) de una mutación de envergadura estructural que incide, de manera particular, en los siguientes cuatro aspectos del trabajo. En primer lugar, en la considerable reducción de la agricultura, que hasta aquí había sido la más importante actividad económica, y en el aumento de los oficios relacionados con la industria y los servicios (Beck, 2007:60); así, el trabajo deja de ser mayoritariamente agrícola y rural para transformarse en industrial y urbano.

En segundo lugar, el hogar ya no es el centro de la actividad económica y laboral y es reemplazado por la fábrica diseñada (Sennett, 2000:34-44; Beck, 2007:83 y 99; Gratton, 2012:21), un nuevo topos económico y simbólico que proporciona el sustento necesario para sobrevivir y una gran parte del sentido de la existencia. En este inmueble, los obreros encajan en una cadena de producción en la que deben desempeñar una rutina exacta, sobre la que descansa el novedoso orden industrial. Esta rutina, si bien degrada -como se verá a continuación-, al mismo tiempo ofrece protección y seguridad, al estar radicada en tres lógicas racionales: el tamaño, el "tiempo métrico" y la jerarquía. En efecto, la rutina inserta al obrero en un espacio-tiempo de orden. El fordismo y el auge del ingeniero como organizador de la actividad económica, de la producción en masa, de la regulación y especialización del 
trabajo y de su estandarización, requieren de un amplio espacio geométrico que iguala a los obreros y a sus tareas y de algunos compartimentos aislados que expresan tanto la jerarquización de las funciones laborales como la marginación de los obreros de las tomas de decisiones. Por su parte, con el taylorismo, se organiza un "tiempo métrico" como el que se aplica en General Motors, donde se jerarquiza y se compartimenta el horario, dividiéndose las horas en 10 períodos de 6 minutos. Como consecuencia, el paso del hogar a la fábrica conlleva un cambio del espacio laboral y de utilización del mismo, una mayor división y cuantificación del tiempo, como también una superior fractura de estas categorías en unidades más pequeñas y, alternativamente, homogéneas y desiguales. Junto a ello, se produce el paso desde el artesano cualificado al obrero especializado, con una pérdida de "calidad" y de valor del trabajo, más racionalizado sí, pero también más jerarquizado y mecanizado, menos libre y más consumido que vivido.

En tercer lugar se produce, tras la Segunda Guerra Mundial y con el keynesianismo, una alianza histórica entre el capitalismo, el Estado asistencial o de Bienestar y la Democracia (Beck, 2007:14 y 99). En efecto, ahora se ha creado el Estado social-liberal democrático (Requejo, 1990:125), un modelo en el que convergen las ideologías liberales, marxistas y democráticas, así como las respectivas visiones sobre la actividad económica, en general, $\mathrm{y}$, el trabajo, en particular.

Merced a este gran pacto se instituye, en cuarto lugar, la Sociedad del Trabajo, basada en el orden social que combate la pobreza y que religa al individuo con la sociedad. Si a esto se le suma el que se consigue el pleno empleo estandarizado, un consumo masivo y una economía fundada en la seguridad, en la certeza y en las fronteras delimitadas entre el trabajo, el capital y el Estado democrático (Beck, 2007:24 y 99), se entenderá que éste sea el período en el que las democracias disfrutan de una progresiva estabilidad (Held, 1993:273).

Algunos autores han señalado las consecuencias negativas que este planteamiento del mundo laboral tiene para las relaciones sociales. Por ejemplo, Adam Smith considera que la rutina industrial aplaca el carácter humano y reprime la solidaridad, sin olvidar que la sociedad progresa materialmente pero no moralmente. Además, en las fábricas los obreros especializados requieren de poco o nulo esfuerzo de pensamiento o juicio (Sennett, 2000:3840), pierden autonomía (Gratton, 2012:21), se alienan (Marx) y se reifican (M. Weber).

\section{LA CRISIS DEL TRABAJO EN LA SOCIEDAD CONTEMPORÁNEA}

A estos elementos negativos, la Posmodernidad -la "sociedad de la información", del "conocimiento", "líquida", "tardocapitalista"...- suma la pérdida de seguridad en el trabajo. En efecto, el mundo posmoderno representa una etapa de descomposición, de incertidumbre, de sucesivas crisis y de derrumbamiento, en la que termina la descolonización y cae el sistema socialista. Esto último es especialmente relevante, pues con él se desmoronan también las ideologías y dejan al sistema capitalista prácticamente solo en la escena del poder económico mundial (Hobsbawm, 2001:403 y s.). Ahora, además se pondrá en cuestión la prosperidad de las economías y del Estado liberal social democrático (Held, 1993:276), que será ferozmente criticado desde posiciones ideológicas cada vez más polarizadas. En líneas generales, son tres los argumentos de ataque más poderosos que, desde el pensamiento político, se hacen a este tipo de Estado democrático: los neoconservadores, que se centran en el Estado de Bienestar; los neoliberales, que resaltan la imperfección del mercado o del intervencionismo estatal; y, los de tradición marxista, 
que observan una escisión cada vez mayor entre las necesidades esenciales del sistema y las expectativas democratizadoras de los ciudadanos, lo que da lugar a un creciente déficit de legitimación (Requejo, 1990:179-204). Estas críticas, en síntesis, pueden reducirse a dos, las efectuadas por la corriente liberal del "pluralismo democrático" que creen que el Estado está sobrecargado y, las desarrolladas por el marxismo, que entienden que aquel ha entrado en una crisis de legitimidad (Held, 1993:277).

En este panorama de descomposición total, el trabajo también ha entrado en una honda y tal vez irreparable crisis (Tezanos, 2001:70). Y lo más preocupante es que ésta es de calado, estructural, pues se ha producido por la interrelación compleja de cinco fuerzas de cambio que parecen imparables y que, junto a aspectos positivos, traen asimismo consecuencias no deseadas: la tecnología, la globalización, la demografía y la longevidad, los recursos naturales y la sociedad (Gratton, 2012:25). Más adelante, me referiré en detalle a algunos de los efectos dañinos de estas transformaciones para el trabajo, pero permítaseme que ahora indique que se podría definir esta situación general como una "modernización "capitalista" liberada de las ataduras del Estado nacional y asistencial" (Beck, 2007:32); en otras palabras, que el hecho característico de nuestro tiempo -más economía y menos política- deja en manos del capital la solución del problema del trabajo. Si además tenemos en cuenta que el capital solo busca el mayor beneficio con el menor coste posible -privado y público- y que, desde siempre, ha intentado reducir los costos laborales, no parece que por esta vía se vislumbre un verdadero y eficaz desenlace positivo a corto plazo.

Es más, los dos modelos tradicionales de trabajo existentes en Occidente (Sennett, 2000: 54) parecen abocarnos a un callejón sin salida. Por un lado, está el modelo "renano" propio de los Países Bajos, Alemania, Francia, Israel, Italia, Japón y los Países Escandinavos. En los países en los que está vigente no existe pleno empleo, pero sí una especie de correctivo facilitado por el Estado de Bienestar, que ha pactado para ello con los sindicatos y las empresas y que proporciona ayudas a los desempleados que mitigan su dramática situación. A pesar de ello, no se puede evitar que ocurran hechos como la desaparición paulatina de empleos industriales, las numerosas jubilaciones anticipadas y el difícil acceso al empleo de jóvenes y mujeres. A esto hay que añadir que, empujados por las circunstancias o conscientemente, los países bajo este modelo están flexibilizando la regulación socio-laboral a favor del empresariado (Tezanos, 2001:50-1) y una reducción de las competencias del Estado, con lo que se rompe, así, el viejo pacto entre el trabajo y el capital y se debilita el colchón de seguridad que éste representaba para los trabajadores, en general, y los más desfavorecidos, en particular. Como corolario, los excluidos de la alianza le echan la culpa a la democracia, que pierde una parte de su legitimidad (Beck, 2007:155). El segundo paradigma de trabajo, el "angloamericano" que se implementa básicamente en USA y en el Reino Unido, se caracteriza por tener una fe casi absoluta en el capitalismo de libre mercado y por concebir la burocracia estatal como subordinada a la economía. El mercado de trabajo, por su parte, supone un coste reducido, lo que se vincula con los empleos inseguros, esporádicos y mal pagados que ofrece (Tezanos, 2001:50-1). En consecuencia, en este modelo, surgen mayores y profundas desigualdades sociales -los que tienen un buen y bien pagado trabajo y aquellos que no- y un aumento de la violencia de origen social -producida por los que son excluidos del sistema- (Beck, 2007:11).

Estos dos modelos, los dos únicos existentes hasta hoy, sitúan a las democracias occidentales ante un irresoluble y trágico dilema: o pagar la creciente pobreza con una mayor tasa de paro -lo que sucede en el primer modelo- o tolerar un índice escandaloso de pobreza 
con un menor desempleo -lo que tiene lugar en el anglosajón-, pero reduciéndolo con sueldos precarios, con baja productividad, con un nivel mínimo e insuficiente de cobertura y con una mayor desigualdad y criminalidad (Beck, 2007:66). Explicarles (lo que normalmente no hacen los políticos, que inciden, contrariamente, en proclamar que son factibles políticas de pleno empleo) a los jóvenes, a las mujeres, a los parados de larga duración y a los mayores de 45 años -los sectores con mayor índice de paro- estas dos únicas posibilidades con las que cuentan los Estados para resolver su dificultad, desde luego, no es ofrecerles demasiadas esperanzas. Ciertamente, las dos soluciones son parcas, insuficientes, $\mathrm{y}$, teniendo en cuenta además que ya llevan en práctica desde los años 80 del siglo pasado, pareciera como si el conjunto del sistema fuera incapaz de plantear verdaderas alternativas, como si estuviera paralizado, como si adoleciera de falta de creatividad, como si se hubiera colapsado y, en suma, como si se hallara al final de una etapa.

\section{LAS TRANSFORMACIONES EN LA ESTRUCTURA OCUPACIONAL Y SUS CONSECUENCIAS}

Los datos disponibles sobre el trabajo en el conjunto de Occidente confirman lo que acabo de señalar: que se están produciendo importantes cambios estructurales generales con respecto a la tradicional sociedad industrial (Tezanos, 2001: 31 ss). Por un lado, se amplifica el porcentaje de la población activa -ahora está en el $62 \%$ - compuesta mayoritariamente por profesionales, técnicos, directores y empleados de cuello blanco, mientras que se achica el trabajo agrícola y el personal de servicios sin cualificación, así como los trabajadores manuales no agrícolas, de la industria y de los servicios. Al lado de esta desmanualización, se produce también una diversificación de las clases trabajadoras y una multiplicación de las especializaciones y cualificaciones. Por otra parte, aumentan los trabajos de peor calidad, los temporales y a media jornada y surgen nuevos fenómenos de precarización laboral y de paro estructural de larga duración y, con ellos, diferencias salariales y de niveles de vida, sin olvidar que, al mermar considerablemente la oferta de trabajo disponible, al acortarse las jornadas laborales y al crecer la instalación de robots industriales, los tiempos del trabajo se sustituyen paulatinamente por los del ocio. Los datos disponibles sugieren que están surgiendo nuevas modalidades y experiencias laborales proporcionadas por la población femenina activa y por profesionales y técnicos, además de por el crecimiento de los trabajadores inmigrantes, por el envejecimiento de las poblaciones activas y por las crecientes dificultades de los jóvenes para encontrar empleo.

En definitiva, el nuevo paradigma ocupacional del trabajo se caracteriza por maximizar la producción, pero flexibilizando y reduciendo el empleo. Todo ello inclina a pensar que la crisis es estructural, que el futuro del trabajo es cada vez peor y que posiblemente éste no tiene futuro.

Este panorama desolador está trayendo consigo hondas repercusiones. En primer lugar, la desmanualización remite, una vez, más a la separación entre el trabajo y el cuerpo, y a la abstracción que éste representa. Sin embargo, esto no quiere decir que lo manual haya sido reemplazado por lo intelectual, puesto que las funciones más inteligentes están siendo desarrolladas por máquinas. Así que no son los robots mecánicos los esclavos del sistema sino los trabajadores que, al no poder optar por usar ni su cuerpo ni su inteligencia, se convierten en seres no libres. De este modo, se asimilan a los mismos robots que los sustituyen, sin que existan diferencias ostensibles, de calidad, entre los robots humanos y 
los mecanizados. Eso sí, estos últimos son más baratos y, por eso, son escogidos por los empleadores, los únicos seres que, en este sentido, pueden optar libremente dentro del sistema.

En segundo lugar, se multiplica la división del trabajo iniciada en la Modernidad, debido al aumento de las especializaciones y de las cualificaciones, lo que trae aparejado una mayor fractura en el trabajo, similar a la existente en la del conjunto de la sociedad, pues éste deviene un objeto autónomo separado de la totalidad (Bauman, 2003:151). El trabajador, por su parte, concentrado en una porción del proceso laboral o en una de sus parciales dimensiones, pierde de vista definitivamente el conjunto de la tarea y extravía la perspectiva y la coordinación general; ésta, queda en manos de unos pocos, los que más "saben" y los que controlan los magnos procesos de producción. De esta manera, el productor ve limitadas sus ambiciones y sus posibilidades y mermada su capacidad de conocimiento y de creación; ya no constituye un creador en el sentido amplio de la palabra sino un microproductor o, a lo sumo, un fabricante de fragmentos o de piezas dispersas: personaliza una azada en los campos de cultivo, un tornillo en un motor, un vaso en un bar o una letra del teclado del ordenador.

En tercer lugar, varían las clases medias, más complejas y diversificadas, pero también menos ricas -como se verá más adelante-. Al disminuir los trabajadores manuales, se produce en la estructura social algo similar a lo que está sucediendo en las organizaciones empresariales: arriba del todo de la estructura, dirigiendo la sociedad, se halla una pequeña parte, amorfa y fuerte, mientras que la base, que se ha hecho más frágil y reducida, excluye a un mayor número de personas. Además, la estructura social se hace menos vertical y más horizontal, sí, pero de una horizontalidad dividida entre los que tienen trabajo -cada vez menos- y los que no lo poseen; constituye, pues, un tipo nuevo de horizontalidad social que no distribuye las ganancias, que iguala en la pobreza a los trabajadores manuales y a las clases medias venidas a menos. De este modo, tienen lugar dos considerables efectos. Por un lado, la transformación del trabajo -junto a la cultura- en un nuevo criterio de distinción social; y, por otro lado, la aparición de movimientos -"indignados"- que reclaman la evolución desde la actual democracia representativa hacia una democracia más participativa. Más bien el contrario, se ha fortalecido el característico elitismo competitivo de nuestra democracia, según lo veían Max Weber o Schumpeter, quien consideraba que ésta no es el gobierno del pueblo sino "del político" (Held, 1993:182-4). Sin embargo, cabría matizar esta tesis y señalar, de un modo más certero, que en estos momentos la democracia no está dirigida tanto por el político como por el agente económico más poderoso, intransparente y escurridizo que ha dado la historia del desarrollo económico.

En cuarto y último lugar, podría pensarse que los, cada vez más numerosos excluidos del trabajo, pasarían a engrosar la sociedad del ocio, pero es evidente que estas personas marginadas no se pueden dedicar precisamente a ensanchar sus conocimientos, a disfrutar libremente de lo que les apetece o de su situación, a reflexionar y a mejorar la sociedad, lo que sería característico de una verdadera sociedad del ocio. En su lugar, lo que hacen es consumir y hacerlo con mayor fruición -mientras sus pensiones o sus mengües ingresos lo permitan-, como determina el orden económico sustentado en el consumo conspicuo e irreflexivo. Así, los participantes del ocio no se construyen como auténticos sujetos y devienen, por el contrario, individuos consumidos, víctimas de un sistema cruelmente deshumanizado en el que las personas, como los objetos industriales, tan solo poseen un valor de cambio y, por tanto, únicamente sirven como instrumento del beneficio insaciable de algunos pocos. 


\section{LAS CARACTERÍSTICAS DEL TRABAJO EN LA ACTUALIDAD}

Pero cabe profundizar todavía más en la crudeza de la crisis del trabajo contemporáneo describiendo sus principales características (Galbraith, 1984:167 ss; Sennett, 2000:19-145; Tezanos, 2001:22-146; Boltanski y Chapiello, 2002:299-395; Bauman, 2003:99-175; Innerarity, 2004:102-8; Beck, 2006:75 ss; Beck, 2007:9-165; Beriain, 2008:142-164 y 204; Gratton, 2012:21; Roche, 2012:144 ss).

1. La transformación de la sociedad industrial y del trabajo a la sociedad del riesgo constituye tal vez la peculiaridad más sobresaliente de nuestro tiempo. Recordemos que el riesgo, tal y como ha sido definido por U. Beck, consiste en la inseguridad calculable y cuantificable, abarca todos los campos -la economía, la sociedad y la política- y sus dimensiones son la globalización, la ecología, la digitalización, la individualización y la politización del trabajo. Sus consecuencias más destacadas en relación con el trabajo son la desprotección, lo discontinuo, lo impreciso, lo informal y, en suma, la irrupción de lo precario. La precarización se expresa mediante la subcontratación y el aumento del trabajo interino, del temporal y del parcial, lo que obedece a una estrategia doble de las empresas: una política de contratación que permite al empleador tener las manos libres y una nueva política de la estructura de la empresa que posibilita a sus dueños externalizar la mano de obra y ocultarse como tales; de esta manera, consiguen esquivar las constricciones del derecho laboral.

Junto a la precariedad, se desarrolla también una economía de la inseguridad y de la incertidumbre. Con ambas, el futuro se presenta oscuro y borroso y muy probablemente peligroso y lleno de riesgos; pero lo realmente novedoso de todo esto es que el Estado y la economía traspasan los riesgos a los individuos y el peso de la incertidumbre del mercado a los asalariados. Si a esto le sumamos que la incertidumbre actual es una poderosa fuerza de individualización, que divide en vez de unir, entenderemos que el peligro se cierne sobre la vida cotidiana de los individuos, llenándola de una angustiosa e incierta espera, o mejor, de una arriesgada desesperanza.

2. El trabajo se define también por la desespacialización y la fragmentación y por la aceleración del tiempo. La desespacialización está impulsada por la contradicción existente entre el capital global y el trabajo local que se presenta fragmentario a nivel planetario. La paradoja del fenómeno consiste en que la proximidad social convive con la distancia geográfica, esto es, que los humanos viven y laboran localmente aislados y globalmente conectados. Así, el capitalismo ha reforzado el valor del lugar y aumentado el deseo de comunidad, pero simultáneamente avanza la desaparición de las barreras, la desfronterización, la desterritorialización, la desespacialización de lo social, de lo político y de la producción y la correlativa "desocialización" del trabajo, que lo está conduciendo a su virtualización. Como supo ver Marx, cuando -en la Revolución Industrial- el trabajo es considerado una mercancía separable de quien lo produce, se convierte en una fícción jurídica. Pero, ahora, en una gran parte, ha perdido también su ubicación definida en la fábrica y se ha situado en un espacio que cambia continuamente o en un sin-lugar, impreciso y desorganizado, donde ya no parece fabricarse nada aparte de los conceptos o ideas, o peor, de los abstractos beneficios desgajados de lo social, del contrato capitaltrabajo-Estado. De este modo, el trabajo se vuelve algo tan virtual como los bits que viajan a la velocidad de la luz por el interior de los ordenadores y, en este sentido, nuevamente nos lleva a su desconexión del cuerpo humano y a la des-consideración del mismo como algo mental, ficticio, invisible y líquido. Parece ilógico que, en tiempos de escasez del 
trabajo y cuando éste debería estar mejor considerado, no revierta caracteres más sólidos sino más etéreos, ajustándose cruelmente a la profética frase escrita por Shakespeare, Marx y Marshall Berman de que, en la Modernidad, "todo los sólido se desvanece en el aire".

Sin lugar a dudas, la deconstrucción del espacio del trabajo se correlaciona con una novedosa construcción del tiempo que se ha desorganizado, que ha acelerado la velocidad y que se representa con una flecha rota y metamorfoseada en un punto que expresa la máxima y concentrada confianza en un presente narcisista. Causa o fruto de ello, el capital se torna más "impaciente" por el deseo de rendimiento rápido, de manera que impulsa vertiginosos y discontinuos cambios institucionales con la creencia de que el crecimiento mejora. Se piensa más en el corto plazo, lo que hace difícil que el ser humano, de naturaleza biológica más lenta, asimile la velocidad del proceso, lo que conduce -como se verá en la última característica del trabajo- a una corrosión del carácter, en especial, de aquellos aspectos que unen entre sí a los humanos y les otorgan la sensación de un yo sostenible y social. En efecto, ahora se produce un conflicto entre el carácter -duradero- y una experiencia del tiempo desarticulada que está impidiendo su consolidación y la de las narraciones duraderas que lo definen. Ello se completa con la flexibilización horaria, especialmente en las grandes corporaciones donde los horarios fijos están en retroceso. Un ejemplo de ello lo encontramos en Toyota, donde se han suprimido todos los tiempos muertos y se ha aumentado al máximo el ritmo de trabajo, o lo que es lo mismo, la intensidad de la actividad con el mismo salario. Al mismo tiempo, hay una escasa valoración de la experiencia acumulada, con la acentuación del desprecio o la desconexión del pasado y con la concentración en lo inmediato. Como escribió Henry Ford, en el Chicago Tribune, el 25 de mayo de 1916, "la historia es una pavada. Nosotros no queremos tradición. Queremos vivir en el presente, y nos importa un bledo la historia que no sea la que hacemos hoy". Esta pasión por el presente ha llegado a tal extremo que el trabajo ofrece hoy "duración a lo efímero" y pierde su consistencia y su continuidad, la memoria, y, sin ella, ya no queda fusionado con la biografía personal. En consecuencia, el trabajo deviene un esclavo del tiempo y, más específicamente, del presente, del momento que tiraniza, desmemoriza y congela nuestras vidas en un instante: ¿no queda, así, el trabajo convertido también en un tirano?

3. La flexibilidad, la desregulación y la informalización, constituyen otros aspectos conformadores del trabajo y son consecuencia de un sistema de poder de la economía que posee tres elementos caracterizadores: la reinvención discontinua de las instituciones -a la que acabo de referirme-; la concentración centralizada del poder -a la que luego me referiré- y la especialización flexible de la producción. Esta última tiene como objetivo conseguir productos cada vez más variados y rápidos, debido a la inestabilidad de la demanda del consumo, y esto se relaciona con el hecho de que la desregularización de las relaciones laborales permite una más rápida transformación de las instituciones de la sociedad.

4. El impacto de las nuevas tecnologías y el paso de la sociedad industrial y terciaria a la del saber y la información constituyen otra importante característica del trabajo. Al respecto, caben cuatro consideraciones. La primera, que la vinculación del mercado global con las nuevas tecnologías representa el sello distintivo del capitalismo contemporáneo, que no es otro que el fin de la sociedad laboral, en la medida en que las personas son sustituidas por las tecnologías. En efecto, el saber, no el trabajo, manifiesta ahora la principal fuente de riqueza social, pero la sociedad del saber no genera más empleo, es más, incrementa la productividad sin generar puestos de trabajo. Los efectos son más que visibles, ya que, con la máquina- 
robot, los trabajadores son cada vez más prescindibles, lo que se une a su alienación, a su desapropiación social y, en suma, a su conversión en no sujetos sociales.

La segunda consideración a tener en cuenta tiene que ver con el llamado desempleo tecnológico, resultado de un nuevo modelo de crecimiento económico que no genera puestos de trabajo y que, cuando lo hace, son de peor calidad. La gran paradoja es, por tanto, que en las sociedades tecnológicas existe una mayor riqueza, pero un menor y más malo empleo.

La tercera consideración se relaciona con el contexto global del empleo y del paro. Es un hecho que la robotización se produce a un ritmo superior al de las nuevas fuentes de trabajo; y que éste no ha crecido desde los años 60 -cuando se logra un pleno empleo- e, incluso, que se mantiene -en los años 2000- en torno a un 30\% de desempleo.

Finalmente, la cuarta consideración, en lo que se refiere a las incidencias de las nuevas tecnologías en el trabajo, son las secuelas generales de la implantación de Internet: la descentralización laboral, la venta en redes con un mayor contacto entre los productores y los consumidores, los menores costes de comercialización, la organización del trabajo en redes, la flexibilización de las regulaciones contractuales, la extensión de nuevas pautas laborales teletrabajo, autónomos subcontratados...-.

5. Otro factor que configura la actividad laboral en la actualidad es lo que se ha denominado (U. Beck) su "brasileñización". Y es que vamos camino de igualar la situación de Suramérica, donde apenas el 35\% de la población económicamente activa cuenta con alguna protección o ayuda de la seguridad social y donde el $40 \%$ del trabajo es informal. Hasta ahora hemos pensado que Europa suponía la cumbre de la civilización y que de lo que se trataba era de universalizar el mundo, de occidentalizarlo, pero lo que está sucediendo es precisamente lo contrario: China y los países emergentes nos llevan la delantera económica $\mathrm{y}$, en cuanto a las modalidades del trabajo, los países latinoamericanos. Como efecto colateral, esta situación conduce a una pérdida de autoestima, de confianza en los valores y en las capacidades occidentales de solventar con eficacia los grandes problemas laborales con los que nos enfrentamos, otra consecuencia, pues, de la desespacialización del trabajo que conlleva la del territorio y el deterioro de la solidez de sus símbolos. Hasta ahora el deseo de implantar nuestros valores -y muchas veces por la fuerza: el mesianismo político- ha constituido un histórico leit motiv de la actividad exterior europea y norteamericana y representa un enemigo íntimo de la democracia (Todorov, 2012:35 ss). En este sentido, el no considerarnos los mejores puede ser positivo para atemperar nuestros ardores evangelizadores, pero desde luego a un coste enorme, ya que nos sitúa en una clara desventaja económica, laboral y civilizatoria, sin olvidar las implicaciones y sufrimientos en las personas.

6. El trabajo de hoy se presenta, asimismo, jerarquizado y desigual. A pesar del crecimiento de las pequeñas y medianas empresas, han aumentado también las organizaciones en red, en detrimento de la gran empresa de la era industrial. Igualmente avanza la influencia de los conjuntos económicos coordinados de gran envergadura (magnas empresas, grupos, organizaciones en red de independientes y colaboraciones entre empresas y alianzas). Y, sobre todo, progresa la formación de oligopolios en todos los mercados, que extienden su implantación y sus redes de colaboradores más allá de sus fronteras. Se ha pasado, así, de las organizaciones con estructura piramidal a otras conformadas por modernas redes institucionales, más ligeras en su base, determinadas como he dicho anteriormente- por vínculos más débiles y delimitadas por fragmentos y nódulos en red, por una estructura que ya no tiene la claridad de la pirámide -no es más sencilla sino más intrincada- y por una dominación desde arriba, amorfa y fuerte, tanto más 
cuanto más débiles son los lazos humanos. De ahí que, aunque teóricamente se manifieste en los cuadros directivos -herederos del mayo del 68- un cierto repudio a la autoridad y aunque buscan nuevos métodos -menos clasistas y jerarquizados y más participativos- de la actividad laboral, lo que está sucediendo no es que desaparezca la jerarquía sino que se acomoda a los nuevos tiempos; lo que está teniendo lugar es que se pasa de una anterior jerarquía vertical a una más horizontal. En ella, la peor parte -como siempre- la llevan los que están situados en la base -significativamente reducida-, en la parte inferior, donde cada vez más gente es obligada a quedarse en el margen o es desplazada al exterior, fuera del mundo del trabajo y, en último extremo, también de la sociedad y de la democracia.

Al mismo tiempo, se está produciendo una concentración de poder económico, sin centralización, fruto de las fusiones, hasta el punto de que 200 grandes corporaciones están controladas por 150 personas localizadas en cinco países. Esta concentración causa una abismal distancia económica y social. De esta manera, los empresarios más grandes son los que controlan, dirigen y gestionan los asuntos económicos -y específicamente los macroeconómicos-, los pequeños tienen cada vez más difícil sobrevivir en un entorno de gigantes; y, si los ricos son cada vez más ricos, los pobres lo son cada vez más. En este sentido, cabe destacar que, en los últimos años, han disminuido los salarios y han aumentado las rentas del capital. La concentración de poder conlleva, además, un enorme peligro, tanto para el universo laboral como para la propia democracia. Y es que los sindicatos no cuentan en la actualidad con una fuerza similar a la de esas enormes corporaciones, lo que es debido en parte a sus propios errores pero, sobre todo, a las prácticas de esas empresas para debilitarlos. Lo cierto es que el sindicalismo de masas ha evolucionado hasta convertirse en más profesional y menos ideologizado, siendo éste un factor de desindicalización, como atestigua la bajada de las afiliaciones. Por lo demás, este debilitamiento sindical ha corrido parejo a la disminución de la crítica a la empresa capitalista y a la reducción de los conflictos laborales, lo que ha traído como consecuencia la ostensible depreciación de la capacidad negociadora de los sindicatos y de la defensa de los derechos de sus trabajadores -el recorte de estos derechos en los últimos años no formaliza más que una evidente prueba de ello-. En tiempos del dominio económico sobre el político, no ayuda precisamente la existencia de un monopolio de tanto poder concentrado en tan pocas manos, a lo que se suma una inteligente estrategia de invisibilidad de este capital, que no desea fotografiarse, que mantiene sedes empresariales en distintos lugares y que oculta o dificulta conocer dónde ingresa sus impuestos fiscales y donde mueve sus beneficios.

En consecuencia, la concentración de poder está dando lugar a una nueva jerarquización social. Esto se debe, en primer lugar, a la ruptura de los lazos existentes entre el capital y el trabajo que se instituyeron durante la revolución industrial, que se mantuvieron hasta prácticamente los años 80 del siglo XX y que dieron como resultado una estabilidad económica, laboral e institucional y una creciente mejora de las condiciones laborales de los trabajadores. En segundo lugar, se produce la dualización del trabajo asalariado y del mercado laboral: por un lado, tenemos una mano de obra estable, cualificada, beneficiada por un nivel salarial relativamente elevado y frecuentemente sindicada en las grandes empresas; por otro, una mano de obra inestable, poco cualificada, infrapagada, escasamente protegida en las pequeñas empresas que prestan servicios anexos y excluida. Todo esto origina una novedosa polarización social entre los trabajadores -los que cuentan y los que no con trabajo- y que reemplaza a la más vieja existente entre la aristocracia y la burguesía o entre ésta y el proletariado. La clase media tampoco es ajena a este proceso, ya 
que está siendo erosionada, debido a la pérdida de calidad de sus trabajos y de los sueldos que conllevan, así como a las superiores tasas impositivas exigidas por la crisis financiera.

Hay que tener también presente que las empresas europeas y norteamericanas han aumentado la productividad y la competitividad, pero en detrimento de los salarios y de prescindir cada vez más de los costes generados con anterioridad al empleo (educación, formación...) y con posterioridad al mismo (reconstitución de las fuerzas, del desgaste y del envejecimiento). Estos costes han sido asumidos por el Estado del Bienestar, pero al entrar éste en crisis ya no ha podido hacer frente a los mismos, lo que ha propiciado la ruina del capital social. Por ejemplo, en USA ha descendido la participación electoral -solo el $30 \%$ de los votantes participan en las elecciones- y se ha producido un "milagro carcelario" con cifras de 500 reclusos por cien mil adultos, en contraste a los 80 por cien mil de Alemania. Mientras tanto, en Europa sucede casi lo mismo, con la excepción, quizás y de momento, de los datos carcelarios y de violencia y de los de participación política, sensiblemente superiores a los de Estados Unidos de Norteamérica. Pero el peligro de la abstención en próximas convocatorias electorales es muy fuerte, como lo es el del ascenso de los extremos del arco político y de movimientos populistas y de extrema derecha. Por estos motivos, me parece conveniente remarcar que el embate contra el Estado del Bienestar y las políticas neoliberales y neoconservadoras de tan desastroso alcance social están siendo producidos por manos invisibles, sí, pero no por seres descarnados o virtuales; la virtualidad del trabajo responde a intereses y a objetivos muy precisos de agentes económicos reales.

7. El último rasgo que manifiesta la actividad laboral contemporánea en Occidente es su individualización y la corrosión del carácter que trae aparejada. En efecto, crece la individualidad en las condiciones laborales y, en particular, en las remuneraciones. Pero la individualidad se manifiesta también en el deterioro de las condiciones de la faena en equipo, pues ésta se ha hecho más superficial, de manera que la comunidad -laboral- se ha convertido en una "fícción". Igualmente la desintegración de la comunidad de trabajo se produce por la utilización, en un mismo espacio, de trabajadores procedentes de empresas diversas y sujetos a distintos estatutos, lo que conduce al desarme y la desorientación de la acción colectiva $\mathrm{y}$, en suma, a una individualización de las faenas.

Ahora bien, no se está hablando de una auténtica individualidad, sustancial, de ideas y de emociones singulares, sino, más bien, de un tipo de individualismo que se parece al de la actividad solitaria del consumo y que, por tanto, es más consumido que vivido. Y es que la vida íntima y emotiva del trabajador va a la deriva ante la creciente dificultad de compaginar las responsabilidades personales y familiares con las laborales. No en balde, al trabajador, progresivamente y sin límites, se le están exigiendo -como se ha visto- horarios más flexibles, disponibilidad total, un paulatino aumento de responsabilidad y se le somete diariamente a una enorme presión para alcanzar los objetivos y los fines, para competir en un universo extremadamente cruel e inasumible donde los beneficios deben ser cada vez más cuantiosos y veloces. Así, el trabajo ya no personifica, desde luego, un placer sino más bien un tripalium, un instrumento de tortura: ¡qué poco hemos avanzado desde el origen del concepto hasta hoy! A esto se le añade que ya no proporciona un modelo ético, en tanto que se produce un conflicto entre sus valores -la finalidad a corto plazo, la racionalidad instrumental sujeta a fines y no a emociones, la competitividad, la insolidaridad...- y los personales y familiares -las obligaciones, los comportamientos honrados, la solidaridad, la empatía y comprensión con el otro...-. 
Así se entiende que el carácter del trabajador se vaya corroyendo poco a poco, que el trabajo ya no constituya una fuente fundamental de conformación de la personalidad, sino lo contrario. Y es que -como había indicado anteriormente- si el carácter se forja en los aspectos duraderos -a "largo plazo"- de nuestra experiencia emocional, una labor cortoplacista que olvida el pasado, que no tiene en cuenta la experiencia, que deja fuera las emociones y que sustituye la inteligencia humana por la mecánica, ya no posibilita la conformación del carácter. Por todo ello, el trabajo tampoco es legible, comprensible para el trabajador, en la medida en que éste no comprende lo que está haciendo o, en el mejor de los casos, solo lo hace de un modo superficial, empujándole a la indiferencia y proporcionándole una frágil identidad laboral.

\section{ANÁLISIS DE ALGUNAS ALTERNATIVAS ANTE LA CRISIS DEL TRABAJO}

Frente a esta situación, se han propuesto algunas alternativas. Una de ellas es la de U. Beck (2006:177-234), quien anuncia tres escenarios de futuro: sin sociedad del trabajo, sociedad del ocio y posnacional y sociedad cívica y política. Beck cree que la antítesis de la sociedad laboral no es la del tiempo libre o del ocio, puesto que éste se mantiene prisionero del imperialismo del valor del trabajo. Lo que defiende es que hace falta una nueva sintonización del Estado, de la sociedad civil y política y del mercado. En efecto, desde su perspectiva, es necesario potenciar la sociedad política de individuos, una sociedad civil activa, en el contexto de una democracia europea que tiene que ser, a la vez, local y transnacional. Partiendo de esta idea, su propuesta se centra concretamente en lo que él llama "trabajo cívico" pagado con "dinero cívico", es decir, un tipo de ocupación no sufragada por el Estado sino por los ciudadanos, que complementa y no sustituye al normal (por cierto, cada vez menos normal) y que se encarga de atender tareas como, por ejemplo, el cuidado de ancianos o de niños, así como la limpieza y mantenimiento de los jardines o de los bosques públicos; se pasaría, así, del ciudadano trabajador al cívico.

La propuesta es, sin duda, interesante, pero, aunque supone un complemento no desdeñable, es sin duda menor, sin olvidar que no puede solventar la difícil situación de la actividad laboral Además, teniendo en cuenta el empobrecimiento creciente de la clase media y de amplias capas populares, el trabajo cívico supondría una nueva merma de sus ingresos y, en último extremo, un debilitamiento económico de estas clases sociales que están en un claro descenso en USA y en Europa y, de un modo agudizado, desde la actual crisis económica. Para que el trabajo cívico se notara realmente, para que su porcentaje fuera mínimamente destacado, primero debería desaparecer la crisis económica financiera, que los Estados y los particulares puedan pagar sus deudas, que los países vuelvan a la senda del crecimiento y que el conjunto de los trabajadores y de las clases medias tengan un respiro.

Lynda Gratton (2012: 29-59), por su parte, considera que son tres los cambios que se van a producir en el futuro: el fin del conocimiento general y superficial, el cuestionamiento del individualismo y de la competitividad y la interrogación acerca del tipo de actividad laboral al que aspiramos. Ante estos cambios, propone que nos preparemos con optimismo para un tipo de conocimiento serial, especializado y cualificado, un trabajo conectivo, colaborativo y en red y una actividad centrada no en el consumo y en la cantidad sino en la producción y la calidad de nuestras experiencias y en 
el equilibrio de nuestras vidas. Constituye éste -según la autora- un "futuro elaborado", de creación conjunta, de participación social, de microemprendedores y de vidas creativas.

Las propuestas de Gratton me parecen interesantes y suponen una corriente de aire fresco, llena de conocimiento sobre el mundo del trabajo y de optimismo, pero, sinceramente, el estado de cosas no invita precisamente a una excesiva esperanza. El conocimiento especializado, seriado y cualificado al que ella nos convoca ya está aquí, pero convive con la escasa valoración de la experiencia, del conocimiento acumulado que es, precisamente, el que posibilita la calidad de la especialización. Por eso, entiendo que a su propuesta debería añadírsele que la edad fuera considerada un valor y no un problema, algo muy difícil en una sociedad que ha caminado en las últimas decenas de años hacia un culto caricaturizado y excesivo de lo joven y hacia un desprecio o minusvaloración de lo maduro: ¿acaso, los mayores de 45 años no constituyen, significativamente, uno de los sectores poblacionales con mayor índice de paro? Tampoco se puede decir que lo que le interesa hoy al mercado de trabajo sean los valores de la juventud -su frescura, espontaneidad, iniciativa y potencia de renovación-, que ellos vayan a ser los especialistas del futuro, sino más bien que constituyen mano de obra barata y fácilmente intercambiable: ¿no es cierto que los jóvenes engrosan hoy considerablemente las listas del desempleo y las de los contratos basura, de los trabajos temporales y de los "mileuristas"?

Ciertamente, sería necesario una mayor conectividad, un reforzamiento del trabajo en equipo y en red, pero es más fácil que eso ocurra en el interior de las empresas que en contactos libres y exteriores. Por ejemplo, las que poseen una fuerte carga tecnológica, siempre sensibles a la piratería industrial, ¿permitirían que sus empleados más cualificados plantearan dudas o cuestiones sobre su trabajo a agentes externos?

Tampoco me parece probable que los tiempos venideros vayan hacia la disminución del individualismo o de la competitividad, sino más bien a lo contrario, a un reforzamiento de uno y de otra. Habría que cambiar toda una cultura social y empresarial -particularmente, en el caso norteamericano-, lo que representaría un esfuerzo considerable de muy largo alcance o, de ser corto, revolucionario. Al respecto, se debe tener en cuenta que la especialización y el individualismo siempre han marchado juntos, que los trabajos menos especializados se han hecho, de forma masiva, en una cadena de montaje o en oficinas abarrotadas, por lo que no es excesivamente coherente proponer el aumento de uno y la disminución del otro.

Finalmente, la alternativa de Gratton peca de optimismo y de un cierto utopismo porque en un tiempo -el de hoy- en el que no podemos escoger ni siquiera un trabajo, ¿cómo podemos seleccionar la calidad del mismo, el que mejor se ajuste a nuestras experiencias y aspiraciones? Lo que primero tenemos que lograr en el futuro es que todas las personas tengan acceso a un puesto laboral -lo que no parece, de momento, factible- y, una vez conseguido esto, que todas puedan escoger la actividad deseada.

\section{REFLEXIONES FINALES}

(1) El estado actual del trabajo en las sociedades occidentales y cómo ha llegado a ser lo que es.

Como se ha podido comprobar en este artículo, el trabajo ha entrado en una profunda crisis estructural, pues ha perdido su seguridad en el contexto del cuestionamiento de la prosperidad de la economía, del Estado de Bienestar, del propio Estado y de la democracia. 
En último extremo, lo que se ha producido es una modernización capitalista, liberada de las ataduras del Estado nacional y asistencial o, lo que es lo mismo, han vencido las posiciones neoconservadoras y neoliberales impulsadas, a su vez, por el triunfo del capitalismo, que se ha quedado solo en la escena económica mundial. Pero el capitalismo olvida que se puede morir de éxito, lo que le puede ocurrir si no sabe encontrar la salida del túnel en el que se halla.

Se están produciendo hondas transformaciones estructurales que indican que el futuro del trabajo es cada vez peor e, incluso, que no hay futuro. Estas transformaciones vienen, además, acompañadas de muy dañinas consecuencias.

(1) La desmanualización del trabajo, que separa aún más al operador de su cuerpo, aumenta la abstracción de la labor. No extrañe, pues, que el trabajador, sin cuerpo y sin inteligencia, deje de ser libre y que se convierta en un robot, eso sí, más barato que el mecánico que le está reemplazando.

(2) La multiplicación de la división del trabajo, por su parte, produce que éste se fracture aún más, que aumente su consideración de objeto autónomo desligado de la sociedad y que el trabajador se identifique con las piezas que fabrica: él mismo es la letra del teclado del ordenador; pero, evidentemente, no es el que la pulsa.

(3) La variación de las clases medias no es mala por sí misma, pero está acompañada de su empobrecimiento generalizado, lo que, junto a la disminución de los trabajadores manuales, está originando una nueva estructura social tan jerarquizada o más como las anteriores. Con la singularidad de que presenta una cúspide pequeña, amorfa y muy fuerte y una base también mínima, pero muy frágil y reducida, que excluye a un mayor número de personas y que divide a los que poseen un trabajo -privilegiados relativos, pues se hallan en la parte inferior del sistema- de los que no. Así, la delgadez y la escasa solidez de la plataforma de la estructura social invitan a plantearse cómo puede sostenerse. Y es que se parece a un tallo que puede ser movido y fracturado por los golpes de viento particularmente donde es más frágil, en otras palabras, que esta estructura social puede tambalearse por los embates de los marginados.

(4) Finalmente, los excluidos no engrosan una posible sociedad del ocio sino, en el mejor de los casos, lo incluyen en el club de individuos consumidos y no producidos y, en el peor, en el de las personas desesperadas que se mueven azarosamente, sin rumbo fijo y caminando hacia el caos.

Precisamente el trabajo debería tratar de evitar este caos, de darle forma a lo informe (Bauman, 2003:146), pero no parece que esto sea lo que está sucediendo sino más bien lo contrario y, así, lo confirman las características que lo definen en la actualidad. Cierto, el trabajo se presenta con riesgo, precario, inseguro e incierto, como consecuencia de que el Estado y la economía traspasan el riesgo a los individuos y la incertidumbre del mercado a los asalariados. La impresión que esto produce es que, cuando parece que el barco se hunde, los primeros que saltan desde la borda para salvarse son el capitán y el contramaestre, dejando a su suerte a la tripulación. En el caso de que aquellos sobrevivan, naturalmente lo harán en un Estado sin ciudadanos y en una economía sin trabajadores.

El trabajo se desespacializa, se fragmenta y acelera su tiempo. Lo primero conduce al debilitamiento del propio concepto del trabajo, convertido en algo mental, ficticio, invisible y líquido, en una entelequia. Por otra parte, un capitalismo cada vez más impaciente genera un pensamiento del corto plazo que domina sobre la reflexión meditada (tanto más necesaria en tiempos de crisis) y valora escasamente la experiencia. De este modo, se reduce el número de personas que pueden trabajar, ya que ahora quedan fuera del 
mercado laboral no solo los niños, sino también los jóvenes que tardan en entrar en él y los maduros que son apartados casi definitivamente. En consecuencia, solo una pequeña franja de edad es considerada útil para laborar, únicamente las personas situadas entre los $30 \mathrm{y}$ los 45 años tienen más posibilidades de tener garantizado un puesto de trabajo. ¿Puede permitírselo el sistema? Es obvio que económicamente no, pero social y culturalmente menos todavía. La transformación del tiempo en el trabajo también implica que se otorgue duración únicamente a lo efímero, al presente, de manera que el futuro no se piensa, pierde entidad y cualidad y, en consecuencia, se vuelve más incierto. Más aún, la concentración en el presente relega también al pasado, que lleva al trabajador a perder su memoria y a la sociedad a borrar la del propio concepto del trabajo, puesto que se termina desconociendo el largo tiempo en que éste estuvo revalorizado para considerar que el trabajo empezó y terminó siendo una tortura: el presente es un tirano; el trabajo, un tirano que tortura.

La flexibilidad, la desregulación y la informalización del trabajo -que daba forma a lo informe y ahora justo a lo inverso- se relaciona con la más rápida transformación de la sociedad, pero también del propio sistema económico capitalista, más flexible, desregularizado e informalizado. Además, el impacto de las nuevas tecnologías en el trabajo comporta que los trabajadores sean prescindibles y que se transformen en no sujetos sociales. La "brasileñización" del trabajo, por su parte, presupone que la Europa y la Norteamérica del primer mundo desciendan de nivel y que se coloquen en una posición de país emergente. Solo que, mientras que Brasil parte de una situación mucho peor pero tiene la esperanza y la probabilidad real de crecer en el futuro, Europa y USA parecen que han extraviado tal esperanza y se sumergen en una situación de claro descenso. Esto no parece algo ilógico, ya que estos últimos están más concentrados -y embarrados, con un cierto deleite victimista- en el desastroso presente que tienen delante, en vez de formular estrategias de porvenir.

El trabajo más jerarquizado y desigual procede de organizaciones que ya no poseen una estructura piramidal sino otra en red y ésta, ciertamente, comunica fluidamente a sus participantes, pero no puede impedir que éstos también se enreden y que, incluso, queden atrapados en una maraña irreconocible. En todo caso, no ha desaparecido la jerarquía, ésta se ha acomodado a los nuevos tiempos y presenta como novedad el desplazamiento hacia más allá del límite de todo aquel que no interesa. No deja de ser sumamente contradictorio que una organización económica tan informal, flexible y desregulada, al mismo tiempo se halle tan autolimitada, o mejor, que esté tan limitada. Por lo demás, el trabajo concentra un gran poder económico en muy pocas manos, lo que conlleva un enorme peligro para el universo laboral porque, aminorados sus lazos con el capital -su contrincante-, se ha visto obligado a oponerse a sí mismo y ha terminado -sin contrario- dividiéndose -dualizándoseél mismo y el mercado laboral. Sin lugar a dudas, el divide y vencerás ha resultado una exitosa y habilidosa estrategia del capital que ha logrado, en tiempos de poderosa ideologización de la economía y de desideologización de los sindicatos y de la política, debilitar a su oponente, el trabajo. A la postre, esto ha permitido que el capital aumente su productividad y su competitividad, a costa de los menores salarios y de las desastrosas consecuencias humanas a las que vengo haciendo referencia aquí.

Finalmente, el trabajo está caracterizado por la individualización y por la corrosión del carácter. Así, si la comunidad laboral y social se han transformado en una ficción, la individualización del trabajo no quiere decir que sea sustancial sino consumida, sin ética y con un carácter corroído, sin personalidad y sin identidad. De este modo, y para sintetizar, 
el trabajo ha devenido algo no legible y sin sentido, o con un sentido tan incierto como su propio futuro.

¿Cómo se ha llegado a la situación actual? Como se ha visto a lo largo de esta investigación, en la Modernidad el trabajo dejó de ser rural para convertirse en urbano y la ciudad es, justamente, ese espacio abstracto construido por los seres humanos: por tanto, el aumento de la abstracción del trabajo durante la industrialización no es sino, en su raíz, un resultado de su urbanización. Por otra parte, la progresiva racionalización del trabajo también ha contribuido considerablemente a su abstracción y a que, en la "economía del acceso" (Rifkin, 2000), termine elaborando ideas y conceptos y no tanto objetos.

En cuanto a la jerarquización del trabajo, ésta siempre ha existido, pero se intensifica y se especializa en la Modernidad y se amolda a nuevas circunstancias en la Posmodernidad, donde se vuelve menos reconocible y más invisible, sí, pero no menos fuerte. No hay que olvidar tampoco que su mecanización, durante la modernización industrial, ha conducido a que el trabajo sea algo menos libre y más consumido que vivido, a lo que se le añade el que la rutina, que produce estabilidad y que hace progresar materialmente, no permite un paralelo aumento de la moral sino la desconexión de la misma. Simultáneamente, al no exigírseles a los obreros en la Modernidad ningún esfuerzo de pensamiento o de juicio, al no permitírseles ninguna autonomía y al alienarlos y reificarlos, se han transformado en cosas, en mercancías. Es la fase precedente a lo que sucede en la Posmodernidad, cuando triunfa la robotización y el momento en el que los obreros, sin cuerpo, sin inteligencia y sin ética, extravían sus últimos resquicios de humanidad mientras laboran y se parecen cada vez más a los robots, a esos seres no libres y más baratos que están sustituyéndolos cruel e implacablemente. Esto es consecuencia del mismo proceso general del capitalismo que tiene que abaratar al máximo el coste laboral para que la mercancía pueda ofrecer la máxima plusvalía al capitalista. Pero no deja de ser absurdo y terrible que los obreros que han construido los robots terminen siendo más baratos que sus propias producciones.

$2^{a}$ El concepto actual de trabajo y de democracia en la que éste se sustenta.

Como se ha comprobado, durante la Modernidad y Posmodernidad ha tenido lugar un proceso de vaciamiento del concepto de trabajo, lo que se inicia cuando se sustituye -en la Revolución Industrial- al artesano cualificado por el obrero especializado, y el trabajo merma en calidad y en valor. Este proceso continúa y se acrecienta durante la Sociedad Posmoderna, momento en el que la definición de trabajo ha adquirido connotaciones ficticias, efímeras, livianas y líquidas. Parece, pues, hoy bastante lejana una concepción del trabajador más humanizada y menos mecanizada y que tenga en cuenta que éste tiene todo el derecho del mundo a vivir su vida, a adquirir experiencia, a madurar y a envejecer; que es un ser humano que siente, que piensa, que vive su vida y sus recuerdos y que éstos quedan depositados en su memoria; que puede forjarse como un individuo profundo, consciente de sus dos elementos constitutivos -la inteligencia y la emoción-; y que es un sujeto político que participa en democracia y que construye la democracia día a día. Y, en cuanto al trabajo, parece evidente que se ha relegado su función de instrumento de esta humanización a la que acabo de hacer referencia, es decir, que se ha obviado que es un importante medio de construcción de sujetos individuales, sociales, políticos y democráticos.

Por lo demás, esta desvalorización del trabajo ha afectado, y mucho, a la calidad de la democracia. Primero porque los dos únicos modelos de trabajo -el renano y el anglosajónque se están implementando en Occidente sitúan al sistema político ante un irresoluble y trágico dilema. Segundo, en tanto que la reducción de la base de la estructura laboral 
conlleva como efecto el que la democracia se haga menos participativa y más elitista; en estos momentos, al tradicional elitismo político, se le añade el de agentes económicos más poderosos y de creciente influencia. Y, tercero, por cuanto que el poder económico se concentra en muy pocas manos, lo que constituye algo contrario a la propia esencia de la democracia, por naturaleza igualitarista, controladora y distributiva del poder.

$3^{\mathrm{a}}$ ¿Es posible reformar el sistema y encontrar soluciones o, por el contrario, éstas no parecen probables y, más bien, lo que manifiestan es que hemos llegado a un final de etapa de contornos más o menos imprecisos, más o menos catastróficos?

Como se ha visto, los remedios puestos encima de la mesa son claramente insuficientes, poco creativos y, lo que es peor, parecen mostrar el colapso o el final de una etapa y del propio capitalismo. También se ha comprobado que el trabajo decrece, que sus condiciones empeoran y que podemos estar ante el final del mismo en las condiciones en las que lo conocemos. Más concretamente, lo que ha acontecido es que, al perder el Estado la anterior seguridad que otorgaba a los trabajadores, quebranta su legitimidad y se convierte, él mismo, en inseguro y con un futuro por delante bastante incierto. El capital, por su parte, al excluir a numerosos trabajadores o al dejarlos en una situación tan precaria, obliga a éstos a que queden fuera del consumo, reduciendo así el mercado y sus ganancias. Ello conduce a los empresarios a buscar nuevos beneficios en el mercado de capitales, de manera que no sería improbable que, una vez que han exprimido al trabajo -su contendiente- y que han roto los lazos con él, terminen compitiendo consigo mismos y enzarzados en un feroz combate para obtener más veloces y cuantiosos beneficios; en suma, la suerte del capital deviene tan arriesgada e incierta como la del Estado. En el caso más extremo, si la tendencia continúa acentuándose, éste disminuirá ostensiblemente el número de sus miembros con plenos derechos -entre ellos, los laborales- o, lo que es lo mismo, reducirá su número de ciudadanos o se quedará prácticamente sin ellos, mientras que la economía contaría con unos pocos trabajadores o los obviaría casi por completo. Cabría preguntarse, entonces, qué porvenir les acontecería al capitalismo y al Estado sin trabajadores-ciudadanos y, en todo caso, el Estado-liberal-social-democrático -el nuestrotendría los días contados.

Lo cierto es que la Sociedad del Trabajo se tambalea con el aumento imparable de la precariedad y de la desocupación, con lo que esta sociedad deja de ser propiamente laboral y comienza a ser reemplazada por otra de perfiles todavía tan difusos y amorfos como los de los capitalistas que mueven el cotarro. Sin embargo, sí está claro que crece el desempleo $\mathrm{y}$, en este sentido, cabe recordar que este término no está socialmente muy valorado; más bien, supone un carácter negativo que expresa "no ocupación", "no pertenencia" y que, en último extremo, comporta que los desempleados estén pero no estén en la sociedad, que habiten en ella sin vivirla. En suma, la reducción de sus miembros comporta que la sociedad se debilite, al igual que lo hace el trabajo que la produce.

¿Estamos, pues, ante una Sociedad Postlaboral y frente a una nueva civilización? Es pronto para decirlo. Lo que sí parece que está sucediendo es que la Sociedad del Trabajo se está deconstruyendo, que las tradiciones y las formas de trabajar que conocemos se están deteriorando lentamente en las últimas décadas y, rapidísimamente, desde la crisis económica reciente. Lo que sí se aprecia es una profunda variación estructural laboral y, en paralelo, también se están desgastando -es lo que sucede en Europa, y señaladamente en España- la legitimidad de los políticos, de las instituciones y de la democracia y están cambiando los estilos de vida que le están asociados, de manera que varía asimismo el sentido de la existencia y de la civilización que la enmarca. Así pues, más que de crisis -se 
alarga demasiado; al menos, desde principios del siglo $\mathrm{XX}$ se viene hablando ininterrumpidamente de ella-, quizás deberíamos referirnos a un final de etapa, que todavía no ha concluido y que, por tanto, aún no ha iniciado algo nuevo.

¿Qué hacer, entonces, ante estas implacables transformaciones? Sinceramente, no veo desenlaces fáciles. Las alternativas que plantean los especialistas -aquí se han analizado dos- constituyen parches al problema y no parece que vayan a solventar, a corto plazo y con eficacia, los graves problemas que se avecinan y, mayormente, los relativos al trabajo. Tampoco pienso que las soluciones revolucionarias sean las adecuadas, pues -como nos ha mostrado el laboratorio de la Historia con sus distintos experimentos- normalmente vienen acompañadas de una gran destrucción, de un numeroso sufrimiento y, lo que es peor, de la muerte de miles de personas; todo ello, para que, al final, solo se produzca un intercambio de posiciones de poder y que se encumbren nuevas élites, quedando el resto de la población al margen. Por este motivo y aunque existen voces que indican que lo que habría que hacer es acabar con el capitalismo, sinceramente no me parece nada fácil, dadas las experiencias totalitarias del siglo XX: ¿cómo lo hacemos y por qué lo sustituimos?

Soy consciente de que el trabajador en paro lo que necesita es un empleo y no disquisiciones más o menos profundas, pero, desde el ámbito en el que yo me muevo -el del análisis y de la reflexión sociológica-, honestamente entiendo que nos quedan dos caminos razonables. El primero, dar a conocer la situación, manifestar la indignación y las legítimas reclamaciones en todos los espacios y tiempos posibles y utilizando los instrumentos -numerosos, por cierto- que el sistema democrático permite. El segundo, prepararnos para el porvenir, recapacitando serenamente acerca de lo que está sucediendo, de lo que todavía nos puede deparar y de cómo podemos afrontar esta sociedad en la que todo lo sólido se desvanece en el aire. Y, todo ello, con los ojos bien abiertos y de manera crítica y activa, intentando ante todo sobrevivir para que la enorme ola de la crisis o de final de era no nos arrastre y nos destruya y, sobre todo, para que no acabe con la esperanza de que es posible iniciar y vivir tiempos mejores. Vayamos preparando alternativas serias para que lo líquido o lo gaseoso adopten una nueva forma sólida, para conformar una nueva civilización basada en viejos valores revigorizados o creando nuevos. Desde luego, entre éstos, la actividad laboral -sea del tipo que sea- no podrá ser en ningún caso algo menor y deberá enmarcarse en el proceso general de construcción de lo humano. De lo contrario, haríamos poco honor al nombre de "civilización" y entraríamos en una nueva etapa de barbarie, y son ya demasiadas en la Historia.

\section{BIBLIOGRAFÍA}

BAUMAN, Z. (2003), Modernidad líquida, Buenos Aires, FCE.

BECK, U. (2006), La sociedad del riesgo global, Madrid, Siglo XXI.

BECK, U. (2007), Un nuevo mundo feliz. La precariedad del trabajo en la era de la globalización, Barcelona, Paidós.

BELL, D. (1992), Las contradicciones culturales del capitalismo, Madrid, Alianza.

BERIAIN, J. (2008), Aceleración y tiranía del presente. La metamorfosis en las estructuras temporales de la modernidad, Barcelona, Anthropos.

BOLTANSKI, L. y CHIAPELLO, É. (2002), El nuevo espíritu del capitalismo, Madrid, Akal.

GALBRAITH, J. K. (1984), La Era de la Incertidumbre, Barcelona, Plaza \& Janés.

GRATTON, L. (2012), Prepárate: el futuro del trabajo ya está aquí, Barcelona, Galaxia GutenbergCírculo de Lectores. 
HELD, D. (1993), Modelos de democracia, Madrid, Alianza.

HOBSBAWN, E. (2001), Historia del siglo XX, Barcelona, Crítica.

INNERARITY, D. (2004), La sociedad invisible, Madrid, Espasa Calpe.

MARX, K. (1985), Trabajo asalariado y capital, Barcelona, Planeta-Agostini.

REQUEJO COLL, F. (1990), Las democracias. Democracia antigua, democracia liberal y Estado de Bienestar, Barcelona, Ariel.

RIFKIN, J. (2000), La era del acceso. La revolución de la nueva economía, Barcelona, Paidós. ROCHE CÁRCEL, J. A. (2012), "Tiempo líquido y cultura de la incertidumbre", en International Review of Sociology, Roma, University La Sapienza, Vol. 22, n. 1.

SENNETT, R. (2000), La corrosión del carácter. Las consecuencias personales del trabajo en el nuevo capitalismo, Barcelona, Anagrama.

TEZANOS, J. F. (2001), El trabajo perdido. ¿Hacia una civilización postlaboral?, Madrid, Biblioteca Nueva.

TODOROV, T. (2012), Los enemigos íntimos de la democracia, Barcelona, Galaxia GutenbergCírculo de Lectores.

UÑA JUÁREZ, O. (2010), La importancia geoestratégica del África Subsahariana, Madrid, Ministerio de Defensa.

UÑA JUÁREZ, O. y GUTIÉRREZ RESA, A. (2010), Integración de los inmigrantes a través de los servicios sociales en la Comunidad de Madrid, Madrid, UNED.

\section{Breve currículo}

\section{Juan Antonio Roche Cárcel}

Profesor Titular de Sociología, Universidad de Alicante. Últimos publicaciones: La Sociedad Evanescente, Anthropos, 2009 (publicado en inglés por Logos Verlag, Berlin, 2013), como editor, Espacios y tiempos inciertos de la cultura, Anthropos, 2007 y La Sociología como una de las Bellas Artes, Anthropos, 2012. Autor de numerosos artículos en revistas de España, Europa, USA y Latinoamérica y coordinador de monográficos en las revistas Política y Sociedad, Arte y Poder, 2007; Papers. Revista de Sociología, Cultura y migraciones, 2009; y Res Publica. Revista de Filosofía Política, Transiciones. La fragilidad de la democracia, 2013. Evaluador de agencias oficiales y revistas de Sociología, ha sido coordinador de investigación: Área de Cultura y Artes de la Asociación Europea de Sociología y Vicepresidente de la Asociación Española de Sociología de la Cultura y de las Artes. 